\title{
Intravenous dexmedetomidine supports bacterial growth
}

\author{
Batai IZ', Ittzes B', Szabó Z', Batai I', Kerenyi M² \\ 'Department of Anaesthesia and Intensive Care, ${ }^{2}$ Department of Medical Microbiology \\ University of Pecs, Hungary
}

\section{Background and Goal of Study:}

Intravenous infusions may be contaminated during preparation or during administration. The contamination rate of intravenous drugs may be as high as $18 \%$ during preparation.(1) These medications may be the source of serious infection if the contaminating bacterium can multiply in the solution (2) . Dexmedetomidine is frequently used as an infusion in intensive care units for sedation. Its administration may improve the outcome of septic patients (3).

In this study we examined bacterial growth in dexmedetomidine

\section{Materials and Methods}

The growth of Staphylococcus aureus (American Type Culture Collection [ATCC] 25923), Escherichia coli (ATCC 25922), and Pseudomonas aeruginosa (ATCC 27853) in dexmedetomidine (Orion) was investigated. Dexmedetomidine was diluted in saline according to the manufacturer's recommendations $(4 \mu \mathrm{g} / \mathrm{mL})$. One $\mathrm{mL}$ diluted dexmedetomidine was inoculated with the above strains and kept at room temperature. The initial bacterial inoculums were $1,5 \times 10^{4}$ colony forming units (cfu) $\mathrm{mL}^{-1}$. At $0,1,2,3,8$, and 24 hours $10 \mu \mathrm{L}$ was plated on Mueller - Hinton (MH) agar. Having incubated for 24 hours at $37^{\circ} \mathrm{C}$ the cfu was counted. Three parallels were performed. Saline $0.9 \%$, MH broth controls and dexmedetomidine sterility check was also applied. Two-way analysis of variance served as the statistical method.

\section{Results and Discussion}

The cfu of all examined strains were unchanged during the first 8 hours. By the end of the experiment $(24 \mathrm{~h})$ the bacterial count of P. aeruginosa and E. coli increased significantly, while the cfu of $S$. aureus remained unchanged in dexmedetomidine. The bacterial growth of $P$. aeruginosa and $E$. coli showed the same pattern in dexmedetomidine and in saline. (Figure 1)
Figure 1. Bacterial growth in dexmedetomidine

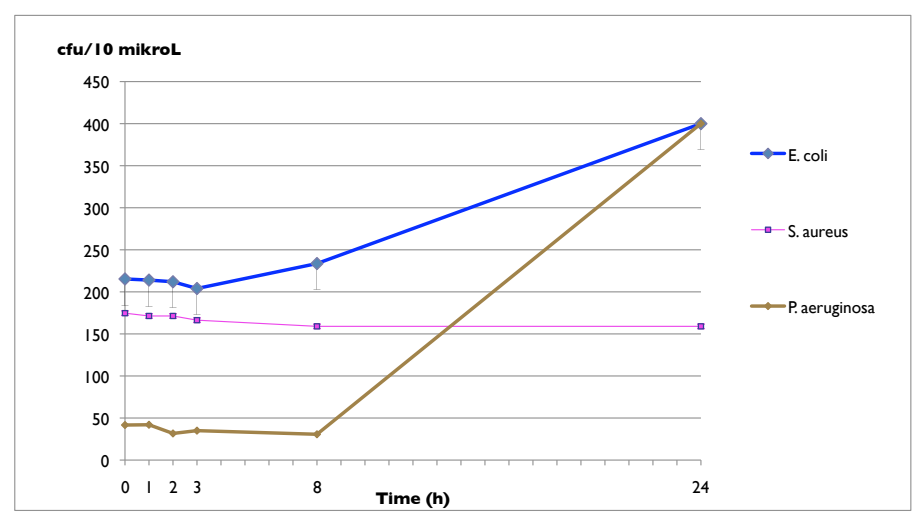

Our results suggest that bacteria survive and after several hours multiply in dexmedetomidine infusion if contaminated. This fact draws the attention for the need of the most careful preparation of dexmedetomidine infusion and the same precautions should be applied as with propofol

\section{Conclusion}

Most of the medications we use in anaesthesia and intensive care inhibit bacterial growth (4). Dexmedetomidine belongs to the few drugs that need extra care when preparing and administering as they support bacterial growth if contaminated.

\section{References:}

(1) Anaesthesia 2007;62:286.

(2) JAMA Intern Med 2014; 174: 606.

(3) Crit Care 2010; 14:R38.

(4) Eur J Anaesthesiol 1999;16:425. 